\title{
Relationship of Weight and Body Mass Index with Femur and Lumbar Vertebrae Bone Mineral Den- sity and Content in Premenopausal Women
}

\author{
Safoura Ghasemi ${ }^{*}$, Heydar Sadeghi ${ }^{1}$, Zahra Basiri², Ahmad Tahammoli Roudsari $^{2}$ \\ 1. Department of Physical Education, Faculty of Physical Education and Sport Science, Kharazmi University, Tehran, Iran. \\ 2. Department of Internal Medicine, School of Medicine, Hamedan University of Medical Sciences, Hamedan, Iran.
}

citation: Ghasemi S, Sadeghi H, Basiri Z, Tahammoli Roudsari A. Relationship of Weight and Body Mass Index with Femur and Lumbar Vertebrae Bone Mineral Density and Content in Premenopausal Women . Physical Treatments. 2015; 5(3):153-162.

do:

Article info:

Received: 20 Feb. 2015

Accepted: 29 Jul. 2015
Keywords:

Body mass index, Bone mineral density, Bone mineral content, Premenopause

\begin{abstract}
A B S T RA C T
Purpose: Given that weight and body mass index (BMI) are considered as modifiable factors in osteoporosis, the present study aimed to examine the relationship of weight and BMI with bone mineral density (BMD) and bone mineral content (BMC) at the femur and lumbar vertebrae in perimenopausal women.

Methods: In this descriptive-correlational study, we measured the bone density of the femur and lumbar vertebrae (L1-L4) of 40 women in perimenopause stage (Mean \pm SD age: $42.85 \pm 1.86$ years; Mean \pm SD weight: $69.55 \pm 10.97 \mathrm{~kg}$; Mean \pm SD height: $159.42 \pm 6.01 \mathrm{~cm}$; and Mean \pm SD BMI: $27.60 \pm 4.04 \mathrm{~kg} / \mathrm{m}^{2}$ ) using a bone densitometry system. The study data were analyzed using descriptive statistics, analysis of variance (ANOVA), the Pearson correlation coefficient, and regression analysis, at 0.05 significance level. All analyses were performed using SPSS v. 21.

Results: Women in the normal group were significantly different from women in the obese group with regard to $\mathrm{BMD}$ and $\mathrm{BMC}(\mathrm{P}=0.001)$. Weight and $\mathrm{BMI}$ were positively correlated with BMD and BMC. Weight and BMI, together, could explain $42 \%$ and $37 \%$ of the variance of $\mathrm{BMD}$ and $\mathrm{BMC}$ at the lumbar vertebrae, respectively; and $70 \%$ and $63 \%$ of the variance of BMD and $\mathrm{BMC}$ at the total hip, respectively.

Conclusion: The results of the present study support the predictive role of weight and BMI in $\mathrm{BMD}$ and BMC. Therefore, future studies are suggested to examine other effective factors with larger samples.
\end{abstract}

\section{Introduction}

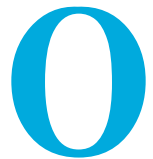

steoporosis is defined as a reduction in bone density and structural changes in bones, and it is regarded as a risk factor for bone fracture [1]. The World Health Organization (WHO) defines osteoporosis as a reduction in bone mineral density (BMD) 2.5 standard deviations below the average value for young and normal individuals ( $\mathrm{T}$ score $<-2.5$ ), and osteopenia as a reduction in BMD 1

* Corresponding Author:

Safoura Ghasemi, PhD Candidate

Address: Department of Physical Education, Faculty of Physical Education and Sport Science, Kharazmi University, Tehran, Iran.

Phone: +98 (918) 8117079

E-mail: std safouraghasemi@khu.ac.ir 
to 2.5 standard deviations below the average value for young and normal individuals $(-1 \geq \mathrm{T}$-score $>-2.5)$, and considers a BMD above that as normal (T-score $\geq-1$ ) [2]. More than 80 factors have been identified for osteoporosis; a number of these factors are more significant. Risk factors for osteoporosis are divided into modifiable and non-modifiable factors. Weight, smoking, low physical activity, low calcium intake, and prolonged glucocorticoid use are among modifiable factors; however, age, race, and genetic predisposition are among non-modifiable ones [3].

Body mass index (BMI) is a common measure of assessing weight and level of obesity [4]. It is calculated as weight in kilograms divided by the square of height in meters [5]. WHO recommends the use of BMI for classification of weight in people above 20 years of age [2]. Body weight less than $57.8 \mathrm{~kg}$ and a reduction in weight $10 \%$ below the weight at the age of 25 years are among the risk factors for osteoporosis [6]. Estrogen is known as an inhibitor of osteoclastic bone resorption [6]. It seems that obesity and gaining body weight in women, due to an increase in the production of estrogen, leads to the suppression of osteoclasts and as a result, an increase in bone density [6]. A high BMI can also, through imposing a high mechanical loading on bones, lead to an increase in BMD [6].

The relationship of weight and BMI with BMD can be explained by the aforementioned mechanisms. However, further investigation may reveal more complex relationships. Being overweight, on the one hand, is a risk factor for cardiovascular diseases, and on the other hand, is believed to have a protective role in bone density. Therefore, in today's world that women tend to lose weight and go on strict diets, it seems necessary to find a balanced relationship between weight and BMI and BMD in women, especially, in the perimenopause stage.

Perimenopause is a stage in a woman's life that begins a few years before menopause, when the ovaries gradually produce less estrogen, and it usually starts at the age of 40 years. The average length of perimenopause is 4 years, but in some women, it may be longer or shorter [1]. Research studies show that keeping an optimum bone density during perimenopause is important in reducing the risk of osteoporosis and subsequent fractures in the postmenopause stage, in which the risk for fractures is 1.5 to 3 times higher [7]. Given that Iran has a very young population, and in the not too distant future, there will be an old population, it is necessary to begin, from the perimenopause stage, to recognize the factors related to osteoporosis. Research studies are needed to reveal the relationship of different factors with bone density in this stage of life, to provide scientific information for women. This can help them control their weight and at the same time, prevent a decrease in their bone density.

Although many studies throughout the world examined the relationship between BMI and BMD, their results are still contradictory. For example, Fares (2013) found a positive relationship between the lumbar vertebrae BMD and BMI [8]. Silva et al. (2007) also showed that BMI was a strong and determining factor in femoral neck and lumbar vertebrae [9]. Bener et al. (2005) concluded that obesity was a protective factor against osteoporosis [10]. Liu et al. (2004) found a positive relationship between $\mathrm{BMI}$ and the BMD at the lumbar vertebrae and total body, in young Chinese women in perimenopause stage [11]. López-Caudana et al. (2004) also showed that BMI was the main predictor of BMD in working women [12].

However, other studies did not find a positive relationship between weight, BMI and BMD. For example, in a study on elderly men, Paniagua et al. (2006) concluded that overweight and obese participants had a lower BMD than normal participants [13]. Robbines et al. (2006) concluded that BMI was not a significant predictor of BMD [14]. Suvithayasiri et al. (2010) found no significant relationship between BMI and the BMD at the lumbar vertebrae in women experiencing menopause [15].

Some previous studies have examined the relationship of weight and BMI with BMC, and have had different results. Jeddi et al. (2012) showed that overweight boys and girls had a higher BMC than girls with normal weight [16]. Cifuentes et al. (2003) found a positive relationship between the total body weight of women experiencing menopause and their BMC [4]. However, Von et al. (2007) found a negative relationship between body fat and bone parameters (BMD/BMC) [17]. Jeddi et al. (2012) showed that the total body BMC of Iranian girls, at all stages of puberty, was lower than that of Lebanese girls. The total body BMC to height ratio (representing the total body volumetric bone density) was also lower in Iranian girls than that of the girls who lived in the United States [16].

It has been documented that reporting on bone density should not be limited to only a single vertebra, because in this way, the risk of osteoporosis is overestimated [3]. It is better to determine the bone density simultaneously at the lumbar vertebrae and proximal femur (the region that involves the most osteoporosis fractures, mortality risk, and socioeconomic costs) [3]. A study is needed to examine the relationship of weight and BMI, simulta- 
neously, with BMD and BMC at the lumbar vertebrae and proximal femur. This research can be useful in explaining the contradictory results of previous studies. The present study aimed to examine the relationship of weight and BMI with BMD and BMC at the femur and lumbar vertebrae in women in perimenopause stage.

\section{Materials and Methods}

\section{Participants}

This was a descriptive-correlational study, and based on the application of its results, an applied research. The statistical population included all 40- 45-year-old women in perimenopause stage, living in Hamadan City, Iran in 2015. Using a convenience sampling method, a total of 40 participants were recruited (using the GPower 3.1 software). The exclusion criteria were as follows: having rheumatoid arthritis; hyperthyroidism or hypothyroidism; parathyroid and adrenal; diabetes mellitus; kidney failure; liver failure; cardiorespiratory disease; neurological disorders; brain injury; lower limb impairments; menopause symptoms; fractures; cancer; menstrual disorder started after the age of 18 years; permanent cessation of menstruation or its cessation in the last 3 months; less than 6 months menstruation in the past year; ovary removal before menopause; infertility, pregnancy, or breastfeeding during the time of study; smoking cigarettes; alcohol consumption; drug addiction; spine deformity; hospitalization due to an illness within 2 weeks prior to the study; complete bed rest for 3 consecutive months; and taking estrogen and progesterone, calcium, multivitamin, vitamin $\mathrm{D}$, and vitamin $\mathrm{D}_{3}$. The research protocol was approved by the Ethics Research Committee (IR.UMSHA.REC.1394.421), and participants' informed consents were obtained. A questionnaire assessing age, height, weight, a lifetime history of fractures, medications, calcium use, physical activity, number of deliveries, the age of first menstruation, pregnancy, and illness was administered to 100 women. Finally, a total of 40 women voluntarily participated in the study.

\section{Anthropometric measurements}

The anthropometric measurements of participants were documented. Height (in centimeters) was measured using a stadiometer with $1 \mathrm{~mm}$ accuracy (after a normal exhale), and weight was measured with minimum cloths and without shoes, using a digital scale with $0.01 \mathrm{~kg}$ accuracy. The BMI was calculated using the following formula:

$$
B M I\left(k g / m^{2}\right)=W e i g h t(k g) \div \operatorname{Height}(m)
$$

According to a classification by $\mathrm{WHO}$, a person with a BMI less than $18.5 \mathrm{~kg} / \mathrm{m}^{2}$ is underweight; 18.5 to 24.99 , normal; 25 to 29.99 , overweight (the range before obesity); 30 to 39.99 , obese; and 40 or higher, too obese.

\section{Clinical evaluations}

A medical specialist assessed the bone density of each participant at the proximal femur and lumbar vertebrae L1 to L4, using a DEXA system (Osteosys, Dexxum-T device, made in South Korea). In the process of assessing bone density by the central devise, after measuring weight, participants laid on their back on the bed of the device, and the receiver of the device was put on parts of their bodies where bone density was intended to be measured. The X-ray directed toward the lumbar vertebrae and femur in the pelvis region. This is a simple, fast, noninvasive, and painless method that does not require general or localized anesthesia. This method measures bone density in 10 to 20 minutes, and uses low-dose X-ray to scan the body. In the present study, the effective dose was 0.10 which is close to the environmental radiation a person receives daily. Before conducting the evaluation, participants were informed about the bone densitometry device and its possible dangers. BMD was calculated in $\mathrm{g} / \mathrm{cm}^{2}$ and BMC was calculated in $\mathrm{g}$, and the results were immediately prepared to be printed by a color printer attached to a computer.

\section{Statistical analysis}

Descriptive statistics (relative frequency and absolute frequency, mean, and standard deviation) were calculated. The Kolmogorov-Smirnov test was used to assess the normality of the measured parameters, analysis of variance (ANOVA) was used to compare group means, the Pearson correlation coefficient was used to determine relationship of weight and BMI with BMD and $\mathrm{BMC}$ at the lumbar vertebrae and proximal femur, and multiple regression analysis was used to examine the effect of weight and BMI on BMD and BMC at the lumbar vertebrae and proximal femur, at 0.05 significance level.

\section{Results}

Table 1 shows the anthropometric characteristics of participants who were divided into 3 groups of normal, overweight, and obese, based on the BMI results. The result of the Kolmogorov-Smirnov test for examination of normality was not significant $(\mathrm{P} \geq 0.05)$, indicating the normality of the data. Therefore, we used parametric analyses. Table 2 shows the bone parameters of the women in perimenopause stage who were divided into 3 
Table 1. Anthropometric characteristics of participants divided into 3 groups, based on the BMI results.

\begin{tabular}{|c|c|c|c|}
\hline Variables & $\begin{array}{c}\text { Normal } \\
n=12 \\
\text { Mean } \pm S D\end{array}$ & $\begin{array}{c}\text { Overweight } \\
n=18 \\
\text { Mean } \pm S D\end{array}$ & $\begin{array}{c}\text { Obese } \\
n=10 \\
\text { Mean } \pm S D\end{array}$ \\
\hline Age (y) & $42.33 \pm 1.83$ & $42.94 \pm 2.04$ & $43.30 \pm 1.64$ \\
\hline Height (cm) & $161 \pm 7.11$ & $159.12 \pm 5.71$ & $158.09 \pm 5.65$ \\
\hline Weight (kg) & $60.55 \pm 6.94$ & $69.17 \pm 7.49$ & $81.02 \pm 10.11$ \\
\hline BMI $\left(\mathrm{kg} / \mathrm{m}^{2}\right)$ & $23.32 \pm 1.63$ & $27.41 \pm 1.83$ & $33.08 \pm 1.80$ \\
\hline
\end{tabular}

Table 2. Means and standard deviations for bone density at the lumbar and hip, and the results of ANOVA comparing 3 groups of participants.

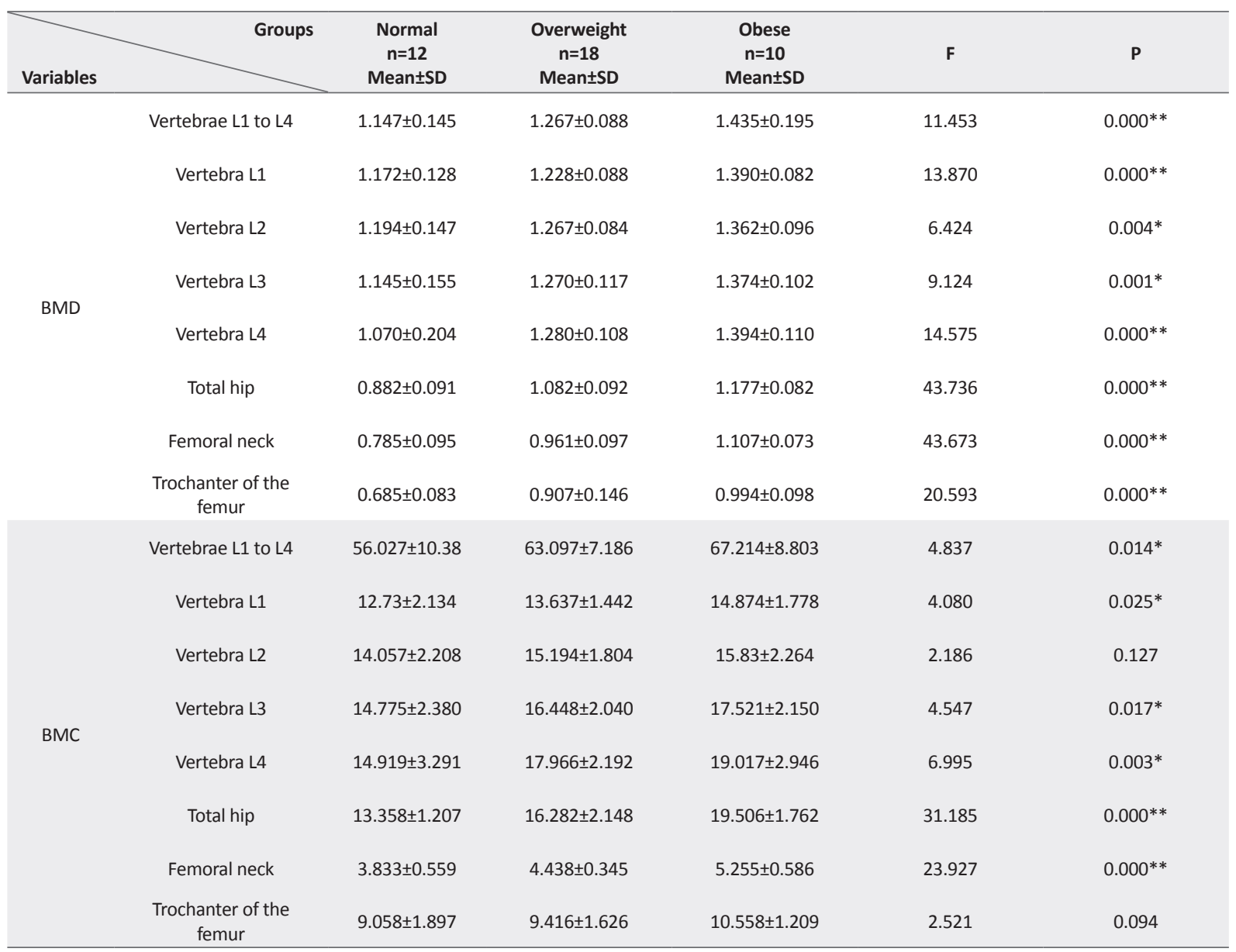

$* * \mathrm{P} \leq 0.001,{ }^{*} \mathrm{P} \leq 0.05$

PHYSICAL TREA TMENTS

groups of normal, overweight, and obese, based on the BMI results. As you can see, the increase of BMD and BMC (except at the L2 and trochanter of the femur) from normal to overweight and from overweigh to obese was more evident (ANOVA). Therefore, there were differences among 3 groups. Post hoc analyses revealed a significant difference between the normal and obese groups, in all parameters $(\mathrm{P}=0.001)$. There was no significant difference between the normal and overweight groups with regard to $\mathrm{BMD}$ at the vertebrae $\mathrm{L} 1$ to $\mathrm{L} 4(\mathrm{P}=0.085)$ and vertebra $\mathrm{L} 1(\mathrm{P}=0.337)$, and also in the $\mathrm{BMC}$ at the vertebrae $\mathrm{L} 1$ to $\mathrm{L} 4(\mathrm{P}=0.104)$, vertebra $\mathrm{L} 1(\mathrm{P}=0.391)$, and vertebra $\mathrm{L} 3(\mathrm{P}=0.133)$. However, there was a significant difference between the two groups for all other param- 
Table 3. Correlation of age, weight, and BMI with BMD and BMC at the lumbar vertebrae and proximal femur.

\begin{tabular}{|c|c|c|c|c|c|c|c|}
\hline \multirow{2}{*}{\multicolumn{2}{|c|}{ Variables }} & \multicolumn{2}{|c|}{ Age (y) } & \multicolumn{2}{|c|}{ Weight (kg) } & \multicolumn{2}{|c|}{ BMI $\left(\mathrm{kg} / \mathrm{m}^{2}\right)$} \\
\hline & & p & $r$ & p & $r$ & p & $r$ \\
\hline \multirow{9}{*}{ BMD } & $\begin{array}{l}\text { Vertebrae } L 1 \\
\quad \text { to } L 4\end{array}$ & 0.180 & 0.216 & $0.000 * *$ & 0.580 & $0.000^{* *}$ & 0.608 \\
\hline & Vertebra L1 & 0.846 & -0.032 & $0.000^{* *}$ & 0.576 & $0.000^{* *}$ & 0.608 \\
\hline & Vertebra L2 & 0.467 & 0.118 & $0.000^{* *}$ & 0.580 & $0.000^{* *}$ & 0.517 \\
\hline & Vertebra L3 & 0.381 & 0.142 & $0.000^{* *}$ & 0.606 & $0.000^{* *}$ & 0.610 \\
\hline & & & & & & & \\
\hline & Vertebra L4 & 0.151 & 0.231 & $0.000 * *$ & 0.634 & $0.000^{* *}$ & 0.645 \\
\hline & Total hip & 0.624 & 0.080 & $0.000^{* *}$ & 0.591 & $0.000^{* *}$ & 0.740 \\
\hline & Femoral neck & 0.639 & 0.076 & $0.000^{* *}$ & 0.659 & $0.000^{* *}$ & 0.750 \\
\hline & $\begin{array}{l}\text { Trochanter of } \\
\text { the femur }\end{array}$ & 0.474 & 0.117 & $0.018^{*}$ & 0.371 & $0.000^{* *}$ & 0.558 \\
\hline \multirow{8}{*}{ BMC } & $\begin{array}{l}\text { Vertebrae } L 1 \\
\quad \text { to } L 4\end{array}$ & 0.419 & 0.132 & $0.000 * *$ & 0.608 & $0.001^{*}$ & 0.498 \\
\hline & Vertebra L1 & 0.981 & -0.004 & $0.000^{* *}$ & 0.560 & $0.004^{*}$ & 0.447 \\
\hline & Vertebra L2 & 0.397 & 0.138 & $0.000^{* *}$ & 0.541 & $0.020^{*}$ & 0.366 \\
\hline & Vertebra L3 & 0.335 & 0.157 & $0.000^{* *}$ & 0.615 & $0.001^{*}$ & 0.504 \\
\hline & Vertebra L4 & 0.169 & 0.222 & $0.000^{* *}$ & 0.600 & $0.001 *$ & 0.524 \\
\hline & Total hip & 0.143 & 0.236 & $0.000^{* *}$ & 0.598 & $0.000^{* *}$ & 0.723 \\
\hline & Femoral neck & 0.559 & 0.095 & $0.000^{* *}$ & 0.602 & $0.000^{* *}$ & 0.700 \\
\hline & $\begin{array}{l}\text { Trochanter of } \\
\text { the femur }\end{array}$ & 0.608 & 0.084 & 0.103 & 0.262 & $0.045^{*}$ & 0.319 \\
\hline
\end{tabular}

** $\leq 0.001, * \mathrm{P} \leq 0.05$.

PHYSICAL TREA $\$$ MENTS

Table 4. The results of multiple regression for dependent variables $\mathrm{y}_{1^{\prime}}, \mathrm{y}_{2^{\prime}} \mathrm{y}_{3^{\prime}}$ and $\mathrm{y}_{4^{\prime}}$, with weight and BMI as independent variables.

\begin{tabular}{|c|c|c|c|c|c|c|c|c|c|c|c|c|}
\hline \multirow{2}{*}{ Dependent } & \multicolumn{3}{|c|}{$\begin{array}{c}\mathrm{y}_{1}=\mathrm{BMD} \text { at the lumbar verte- } \\
\text { brae (L1 to L4) }\end{array}$} & \multicolumn{3}{|c|}{$y_{2}=B M D$ at the total hip } & \multicolumn{3}{|c|}{$\begin{array}{c}\mathrm{y}_{3}=\mathrm{BMC} \text { at the lumbar verte- } \\
\text { brae (L1 to L4) }\end{array}$} & \multicolumn{3}{|c|}{$\mathrm{y}_{4}=\mathrm{BMC}$ at the total hip } \\
\hline & B & & $\mathbf{t}$ & B & & $\mathbf{t}$ & B & & $t$ & B & & $t$ \\
\hline \multirow{3}{*}{ Constant } & 0.76 & & 5.070 & 0.699 & & 7.034 & 26.431 & & 3.116 & 9.016 & & 4.518 \\
\hline & & & & & & & & & & & & \\
\hline & \multicolumn{3}{|c|}{$P=0.000$} & \multicolumn{3}{|c|}{$P=0.000$} & \multicolumn{3}{|c|}{$P=0.004$} & \multicolumn{3}{|c|}{$P=0.000$} \\
\hline \multirow{2}{*}{ Weight (kg) } & 0.005 & & 1.704 & 0.000 & & 0.167 & 0.494 & & 3.164 & 0.024 & & 0.664 \\
\hline & \multicolumn{3}{|c|}{$P=0.097$} & \multicolumn{3}{|c|}{$P=0.869$} & \multicolumn{3}{|c|}{$P=0.003$} & \multicolumn{3}{|c|}{$P=0.511$} \\
\hline \multirow{2}{*}{$\mathrm{BMI}\left(\mathrm{kg} / \mathrm{m}^{2}\right)$} & 0.095 & & 2.357 & 0.175 & & 6.529 & 0.634 & & 0.277 & 2.820 & & 5.246 \\
\hline & \multicolumn{3}{|c|}{$P=0.024$} & \multicolumn{3}{|c|}{$P=0.000$} & \multicolumn{3}{|c|}{$P=0.783$} & \multicolumn{3}{|c|}{$P=0.000$} \\
\hline & $\mathrm{F}$ & $\mathrm{R}^{2}$ & $P$ & $\mathrm{~F}$ & $R^{2}$ & $P$ & $\mathrm{~F}$ & $\mathrm{R}^{2}$ & $P$ & $\mathrm{~F}$ & $\mathrm{R}^{2}$ & $P$ \\
\hline \multicolumn{13}{|l|}{ Model } \\
\hline & 13.565 & 0.423 & $0.000^{*}$ & 42.672 & 0.698 & $0.000 *$ & 10.920 & 0.371 & $0.000^{*}$ & 31.686 & 0.631 & $0.000 *$ \\
\hline
\end{tabular}


eters. There was no significant difference between the overweight and obese groups with regard to MBD at the vertebrae $\mathrm{L} 2(\mathrm{P}=0.101)$, vertebra $\mathrm{L} 3(\mathrm{P}=0.125)$, vertebra $\mathrm{L} 4(\mathrm{P}=0.131)$, and the trochanter of the femur $(\mathrm{P}=0.195)$, and also at the BMC of the vertebra $\mathrm{L} 4(0.464)$ and the trochanter of the femur $(\mathrm{P}=0.628)$. However, there was a significant difference between the two groups in all other cases.

Table 3 shows the correlation coefficients for age, weight, and BMI with BMD and BMC at the lumbar vertebrae and proximal femur. As you can see, weight and $\mathrm{BMI}$ are positively correlated with BMD at all regions $(\mathrm{P} \leq 0.05)$, and the strongest correlation was found between $\mathrm{BMI}$ and the BMD at the femoral neck $(\mathrm{P}=0.001$, $\mathrm{r}=0.750$ ). No significant relationship was found between age and $\mathrm{BMD}(\mathrm{P} \geq 0.05)$. There was a positive relationship between weight and $\mathrm{BMC}$ at all regions (except for the trochanter of the femur) $(\mathrm{P}=0.001)$. Also, positive relationships were found between $\mathrm{BMI}$ and the $\mathrm{BMC}$ at all regions $(\mathrm{P} \leq 0.05)$. The strongest correlation was found between BMI and the BMC at the total hip ( $\mathrm{P}=0.001$, $\mathrm{r}=0.723$ ). No significant correlation was found between age and $\mathrm{BMC}(\mathrm{P} \leq 0.05)$.

Table 4 presents the results of multiple regression (using the enter method) for age and BMI as independent (predictor) variables and the $\mathrm{BMD} / \mathrm{BMC}$ at the lumbar vertebrae (L1 to L4) and total hip as dependent (criterion) variables $(n=40)$. As you can see, BMI explains the most part of the variance of the $\mathrm{BMD}$ at the lumbar vertebrae ( $\mathrm{L} 1$ to $\mathrm{L} 4)(\mathrm{P}=0.024, \mathrm{~B}=0.095)$, the $\mathrm{BMD}$ at the total hip $(\mathrm{P}=0.000, \mathrm{~B}=0.175)$, and the $\mathrm{BMC}$ at the total hip $(\mathrm{P}=0.000, \mathrm{~B}=2.820)$. Weight explains the most part of the variance of the BMC at the lumbar vertebrae (L1 to L4) $(\mathrm{P}=0.003, \mathrm{~B}=0.494)$. Weight and $\mathrm{BMI}$, together, could significantly explain $42 \%$ of the variance of the BMD at the lumbar vertebrae ( $\mathrm{L} 1$ to $\mathrm{L} 4)(\mathrm{F}=13.565), 70 \%$ of the variance of the BMD at the total hip ( $\mathrm{F}=42.672), 37 \%$ of the variance of the $\mathrm{BMC}$ at the lumbar vertebrae (L1 to L4) $(\mathrm{F}=10.920)$, and $63 \%$ of the variance of the $\mathrm{BMC}$ at the total hip $(\mathrm{F}=31.686)(\mathrm{P}<0.001)$.

\section{Discussion}

The goal of the present study was to examine the relationship of weight and BMI with BMD and BMC at the femur and lumbar vertebrae in women in perimenopause stage. The BMD and BMC in the normal group were significantly different from those in the obese group ( $\mathrm{P}=0.001)$, but in some cases, the overweight group was not significantly different from the normal and obese groups $(\mathrm{P} \leq 0.05)$. Age was not significantly correlated with $\mathrm{BMD}$ and $\mathrm{BMC}(\mathrm{P} \leq 0.05)$. There was a positive correlation between weight and BMD. The BMD increased with the increase of weight, and the BMD at the femoral neck had the strongest correlation with weight. There was a positive relationship between weight and BMC, and the third lumbar vertebra (L3) had the strongest correlation with weight. There were positive correlations between BMI and BMD. There was an increase in BMD as BMI increased, and the strongest correlation was between BMI and the BMD of the femoral neck. There were positive correlations between $\mathrm{BMI}$ and $\mathrm{BMC}$, and the strongest correlation was between BMI and the BMC at the total hip. The multiple regression showed that weight and BMI could significantly explain the variance of the BMD and BMC at the lumbar vertebrae (L1 to L4) $(\mathrm{P}<0.001)$.

In a study on 50-79-year-old men, Salamat et al. (2013) found the positive correlation of weight and BMI with the BMD and BMC at the lumbar and hip, and the strongest correlation was found between weight and the BMC at the total hip and the trochanter of the femur [18]. These results are consistent with the results of the present study, but there are difference between the two studies with regard to the age and gender of the participants. Salamat et al. (2013) found a negative correlation between weight and $\mathrm{BMD}$ and $\mathrm{BMC}$, and reported weight as a stronger predictor of BMD and BMC than BMI [18]. Baheiraei et al. (2005) found a positive relationship between age and BMI and the BMD at the femoral neck and lumbar vertebrae [19]. Farrokhseresht et al. (2013) found age to be a significant factor in reduced bone density, and found an increase in the risk for fracture in higher age groups [20]. In a study by Aghaei et al. (2013) a positive relationship was found between age and bone density [21] Vilasdechanon et al. (2011), Soheili et al. (2008), Derakhshan et al. (2006), and Mojibian et al. (2006), reported age to be an important and effective factor in reduced bone density [22-25].

Salekzamani et al. (2009) and Eghbali et al. (2008) also found an increase in the bone density reduction with the increase of age [26, 27]. Larijani et al. (2003) showed that BMD at lumbar vertebrae and femoral neck decreases significantly, every decade after the age of 40 years [28]. Most of the above studies found negative relationships between age and BMD; however, in the present study, no significant relationship was found between age and BMD and BMC. Our different results in this regard may be due to the age range of study participants who were between 40 and 45 years old. Shahidi et al. (2012) found a positive relationship between age and bone den- 
sity, but they found no significant relationship between $\mathrm{BMI}$ and BMD at the lumber vertebrae [30].

Zhao et al. (2007) showed a positive association between weight and BMI and BMD at the lumbar vertebrae [30]. Sordia et al. (2004) showed that shorter height and lower weight are better determining factors (compared to BMI) in osteoporosis [31]. In a study by Liu et al. (2004) weight was not found to be a good predictor of BMD in women in perimenopause, but a positive correlation was found between BMI and the BMD at the total body, vertebral column, and hip [13]. In this study, a positive relationship was found between weight and BMD. BMD increases as the age increases. In fact, body weight and BMD at the femur and lumbar vertebrae that bear mechanical pressures, are highly correlated, but the responsible mechanisms are not fully known. The results of some of the above studies are consistent with the study results, but the age range of participants was different. Researchers believe that higher body weight with adipose tissue, as the main source of estrogen, significantly prevents bone density reduction [32]. On the other hand, given that adipose tissue is the origin of osteoblasts, from a metabolic perspective, it is also considered to be an active tissue that its effects on the bones maybe not only because of its weight effects, but also because of its non-weight effects, such as hormone metabolism [33].

In a study conducted by Hosseini et al. (2014), BMD was reported to increase with the increase of BMI, but no significant difference was found between overweight and obese groups [34]. Arimatsu et al. (2009) showed the positive effect of BMI on the BMD at the lumbar [34]. Sharami et al. (2008) showed that osteoporosis was more prevalent in women with BMI less than 25 than women with BMI greater than 25 [36]. Morin et al. (2009), Silva et al. (2007), El Maghraoui et al. (2007), Asomaning et al. (2006), Benet et al. (2005), and Castro et al. (2005) also confirmed the positive relationship between BMI and BMD [9-12, 37-40]. Toth et al. (2005), examined the effect of BMI on BMD in men, and found out that the BMD at the femoral neck was significantly higher in obese than thin participants, but no significant relationship was found between BMI and the BMD at the lumbar vertebrae [41].

However, Fawzy et al. (2011) did not find any significant relationship between BMD in overweight and normal participants [42]. Greco et al. (2010) observed that overweight participants had a normal BMD, but obese participants had a low BMD [43]. Paniagua et al. (2006) also showed that reduced bone density was more prevalent in overweight and obese, elderly men [10]. Robbines et al. (2006) found that BMI was not a good predictor of BMD [11]. Larijani et al. (2005) found a significant relationship between BMI and BMD in men, but failed to find a significant relationship in women [44]. Barrera et al. (2004) confirmed the positive and high effect of BMI on BMD at the femur region in elderly participants [45]. Lopez-Caudana et al. (2004) believed that BMI was the main determining factor in women [14]. Wu et al. (2002) also showed a positive relationship between BMI and BMD [46]. Sowers et al. (1992) reported that BMI had no determining effect on BMD [47]. In the present study, positive correlations were found between BMI and $\mathrm{BMD}$ and $\mathrm{BMC}$, and weight and BMI could predict the variance of BMD and BMC. Our results were consistent with the results of some previous studies but were not consistent with the results of some other studies. This indicates a need for further research to understand the underlying mechanisms.

The present study had some limitations, such as having a small sample and the age range and gender of the study participants. Future studies are suggested to investigate our study variables with larger samples in different age groups, and to compare the obtained results between men and women subjects.

There was no significant increase in bone density in obese participants compared to overweight ones. Normal-weight participants, compared to overweight and obese ones, had lower bone density. Given that obesity is an important risk factor for osteoporotic fractures, it seems that keeping bone density at a normal level, and reaching a normal weight, along with doing activities that increase mechanical pressure on bones (such as hiking and exercises that involve pressure) are effective methods, which are recommended for women in the perimenopause period in which the hormonal changes resulting from menopause are yet to occur. These findings can be helpful in designing proper strategies for prevention and treatment of osteoporosis.

\section{Acknowledgments}

This paper was extracted from the first author' Ph.D thesis. We sincerely thank all the participating women and also Partow Clinic staff in Hamadan, Iran (Dr Ali Ehsan Saleh) who helped us in conducting this research.

\section{Conflict of Interests}

The authors declared no conflict of interests. 


\section{References}

[1] International Osteoporosis Foundation. Switzerland [Internet]. 2015 [Cited 2015 Aug. 29]. Available from: https:// www.iofbonehealth.org

[2] World Health Organization. Report of a WHO study group. Assessment of fracture risk and its application to screening for postmenopausal osteoporosis. Geneva: World Health Organization; 1994

[3] Geusens P, Hochberg MC, van der Voort DJ, Pols H, van der Klift M, Siris E, et al. Performance of risk indices for identifying low bone density in postmenopausal women. Mayo Clinic Proceedings. 2002; 77(7):629-37.

[4] Cifuentes M, Johnson MA, Lewis RD, Heymsfield SB, Chowdhury HA, Modlesky CM, et al. Bone turnover and body weight relationships differ in normal-weight compared with heavier postmenopausal women. Osteoporosis International. 2003; 14(2):116-22.

[5] National Institute of Health. Clinical guaidlines on the identification evaluation and treatment of owrweight and obesity in adults: the evidence report. Bethesda: National Institute of Health; 1998.

[6] Kameda T, Mano H, Yuasa T, Mori Y, Miyazawa K, Shiokawa $\mathrm{M}$, et al. Estrogen inhibits bone resorption by directly inducing apoptosis of the bone-resorbing osteoclasts. Journal of Experimental Medicine. 1997; 186(4):489-95.

[7] Vondracek SF, Hansen LB, McDermott MT. Osteoporosis risk in premenopausal women. Pharmacotherapy. 2009; 29(3):305-17.

[8] Fares Al-Maitah RK. The relation between T-score, Z-score, bone mineral density and body mass index. Mathematical Theory and Modeling. 2013; 3(5):118-23.

[9] Silva HG, Mendonça L, Conceição FL, Zahar SE, Farias ML. Influence of obesity on bone density in postmenopausal women. Arquivos Brasileiros de Endocrinologia \& Metabologia. 2007; 51(6):943-49.

[10] Bener A, Hammoudeh M, Zirie M, Heller RF. Is obesity a protective factor for osteoporosis? APLAR Journal of Rheumatology. 2005; 8(1):32-8

[11] Liu JM, Zhao HY, Ning G, Zhao YJ, Zhang LZ, Sun LH, et al. Relationship between body composition and bone mineral density in healthy young and premenopausal Chinese women. Osteoporosis International. 2004; 15(3):238-42.

[12] López-Caudana AE, Solıs MM, Hernández-Avila M, Clark P, Juárez-Márquez SA, Lazcano-Ponce EC, et al. Predictors of bone mineral density in female workers in Morelos State, Mexico. Archives of Medical Research. 2004; 35(2):172-80.

[13] Paniagua MA, Malphurs JE, Samos LF. BMI and low bone mass in an elderly male nursing home population. Clinical Interventions in Aging. 2006; 1(3):283-89.

[14] Robbins J, Schott AM, Azari R, Kronmal R. Body mass index is not a good predictor of bone density: results from WHI, CHS, and EPIDOS. Journal of Clinical Densitometry. 2006; 9(3):329-34

[15] Suvithayasiri V, Thaipisuttikul O. The correlation between body mass index and bone mineral density in menopausal women. Vajira Medical Journal. 2010; 46(3):213-22.
[16] Jeddi M, Roosta MJ, Dabbaghmanesh MH, Bagheri Z, Ansari Lari M, Omrani R. [Evaluation of bone mineral density in urban girls of Kawar-Fars (Persian)]. Iranian South Medical Journal Bimonthly. 2012; 15(3):209-20.

[17] von Scheven E. Pediatric bone density and fracture. Current Osteoporosis Reports. 2007; 5(3):128-34.

[18] Salamat MR, Salamat AH, Abedi I, Janghorbani M. Relationship between weight, body mass index, and bone mineral density in men referred for dual-energy $\mathrm{X}$-ray absorptiometry scan in Isfahan, Iran. Journal of Osteoporosis. 2013 2013:205963. doi: $10.1155 / 2013 / 205963$

[19] Baheiraei A, Pocock NA, Eisman JA, Nguyen ND, Nguyen TV. Bone mineral density, body mass index and cigarette smoking among Iranian women: implications for prevention. BMC Musculoskeletal Disorders. 2005; 6:1. doi: 10.1186/1471-2474-6-34

[20] Farrokhseresht R, Solati M, Azizi M, Sarafraz H. [Bone mineral density evaluation of post menopausal women who referred to Shahid Mohammadi hospital BMD center (Persian)]. Medical Journal of Hormozgan University. 2014; 17(6):515-20.

[21] Aghaei M, Sedighi S, Behnampour N, Hezar Khani S, Shirashiani M, Hashemizadeh P, at el. [The Relationship between age and bone mineral density in postmenopausal women with rheumatoid arthritis (Persian)]. Journal of Shahrekord University of Medical Sciences. 2013; 15(2):53-60.

[22] Namwongprom S, Ekmahachai M, Vilasdechanon N, Klaipetch A, Wongboontan C, Boonyaprapa S. Bone mineral density: correlation between the lumbar spine, proximal femur and Radius in northern Thai women. Journal of the Medical Association of Thailand. 2011; 94(6):725-31.

[23] Soheili Azad AA, Golestan B, Jahanbakhsh S. [Determination of the Relation between Osteoporotic and Osteopenic Risk Factors among Women Referring to BMD Center (Persian)]. Razi Journal of Medical Sciences. 2008; 14(57):91-99.

[24] Derakhshan S, Salehi R, Reshadmanesh N. [Prevalence of osteoporosis, osteopenia and their related factors in postmenopausal women referring to Kurdistan densitometry center (Persian)]. Scientific Journal of Kurdistan University of Medical Sciences. 2006; 11(2):59-67.

[25] Mojibian M, Oulia MB, Beiki Bo, Kouchak Yl. [Osteoporosis in postmenopausal women (Persian)]. Iran Journal of Surgery. 2006; 14(1):71-78

[26] Salekzamani Y, Radmanesh M, Shakouri SK, Eslamian F, Akhbarzadeh M, Fallahpour H, et al. Evaluation of bone mineral density in carpet weavers in Tabriz. Annals of Military and Health Sciences Research. 2009; 7(3):208-16.

[27] Eghbali SS, Nabipour I, Dehghani Z. Prevalence of osteoporosis in women older than 50 years old in Bushehr port. Iranian South Medical Journal Bimonthly. 2009; 11(2):163-69.

[28] Soltani A, Pazhouhi M, Bastan H, Mirfeizi S, Dashti R, Hosseinnezhad A. [Bone mineral density variations in 20-69 year population of Tehran/Iran (Persian)]. Iranian South Medical Journal 2002; 5(1):41-49.

[29] Shabani M, Gaeini A, Sajedifar F. [The relationship between anthropometric factors and BMD of lumbar spine in athletic and non-athletic premenopausal women (Persian)]. 
Zahedan Journal of Research in Medical Sciences. 2012; 13(9):27-32.

[30] Zhao LJ, Liu YJ, Liu PY, Hamilton J, Recker RR, Deng HW. Relationship of obesity with osteoporosis. The Journal of Clinical Endocrinology \& Metabolism. 2007; 92(5):1640-646.

[31] Sordia LH, Vazquez J, Iglesias JL, Piñeyro MO, Vidal O, Saldivar D, et al. Low height and low weight correlates better with osteoporosis than low body mass index in postmenopausal women. International Congress Series. 2004; 1271:407-10. doi 10.1016/j.ics.2004.05.041

[32] Reid IR, Plank LD, Evans MC. Fat mass is an important determinant of whole body bone density in premenopausal women but not in men. Journal of Clinical Endocrinology \& Metabolism. 1992; 75(3):779-82.

[33] Reid IR, Mason B, Horne A, Ames R, Reid HE, Bava U, et al. Randomized controlled trial of calcium in healthy older women. American journal of medicine. 2006; 119(9):777-85.

[34] Hosseini S, Sajjadi P, Jamali S, Noreddini H, Ghadimi R, Bijani A. [The Relationship between Body Mass Index and Bone Mineral Density in Older People (Persian)]. Journal of Babol University of Medical Sciences. 2014; 16(7):14-22.

[35] Arimatsu M, Kitano T, Kitano N, Inomoto T, Shono M, Futatsuka M. Correlation between forearm bone mineral density and body composition in Japanese females aged 18-40 years. Environmental Health and Preventive Medicine. 2005; 10(3):144-49.

[36] Sharami SH, Millani F, Alizadeh A. Risk factors of osteoporosis in women over 50 years of age: A population based study in the North of Iran. Journal of Turkish-German Gynecol Association. 2008; 9(9):38-44.

[37] Morin S, Leslie WD. Manitoba Bone Density Program. High bone mineral density is associated with high body mass index. Osteoporosis International. 2009; 20(7):1267-271.

[38] El Maghraoui A, Guerboub AA, Mounach A, Ghozlani I, Nouijai A, Ghazi M, et al. Body mass index and gynecological factors as determinants of bone mass in healthy Moroccan women. Maturitas. 2007; 56(4):375-82.

[39] Asomaning K, Bertone-Johnson ER, Nasca PC, Hooven F, Pekow PS. The association between body mass index and osteoporosis in patients referred for a bone mineral density examination. Journal of Women's Health. 2006; 15(9):1028-034

[40] Castro JP, Joseph LA, Shin JJ, Arora SK, Nicasio J, Shatzkes $\mathrm{J}$, et al. Differential effect of obesity on bone mineral density in White, Hispanic and African American women: a cross sectional study. Nutrition \& Metabolism. 2005; 2(1):9-15.

[41] Toth E, Ferenc V, Meszaros S, Csupor E, Horvath C. Effects of body mass index on bone mineral density in men. Orvosi hetilap. 2005; 146(28):1489-493.

[42] Fawzy T, Muttappallymyalil J, Sreedharan J, Ahmed A, Alshamsi SO, Al Ali MS, et al. Association between body mass index and bone mineral density in patients referred for dual-energy X-ray absorptiometry scan in Ajman, UAE. Journal of Osteoporosis. 2011: 876309. doi: 10.4061/2011/876309

[43] Greco EA, Fornari R, Rossi F, Santiemma V, Prossomariti $\mathrm{G}$, Annoscia C, et al. Is obesity protective for osteoporosis? Evaluation of bone mineral density in individuals with high body mass index. International Journal of Clinical Practice. 2010; 64(6):817-20.

[44] Larijani B, Hossein-Nezhad A, Mojtahedi A, Pajouhi M, Bastanhagh $\mathrm{MH}$, Soltani A, et al. Normative data of bone mineral density in healthy population of Tehran, Iran: a cross sectional study. BMC Musculoskeletal Disorders. 2005; $6(1): 38$

[45] Barrera G, Bunout D, Gattás V, de la Maza MP, Leiva L, Hirsch S. A high body mass index protects against femoral neck osteoporosis in healthy elderly subjects. Nutrition. 2004; 20(9):769-71.

[46] Wu F, Ames R, Clearwater J, Evans MC, Gamble G, Reid IR. Prospective 10-year study of the determinants of bone density and bone loss in normal postmenopausal women, including the effect of hormone replacement therapy. Clinical Endocrinology. 2002; 56(6):703-11.

[47] Sowers MR, Kshirsagar A, Crutchfield MM, Updike S. Joint influence of fat and lean body composition compartments on femoral bone mineral density in premenopausal women. American Journal of Epidemiology. 1992; 136(3):257-65. 
